\title{
Non-coding RNAs enter mitosis: functions, conservation and implications
}

\author{
Jun Wei Pek, Toshie Kai
}

\begin{abstract}
Nuage (or commonly known as chromatoid body in mammals) is a conserved germline-specific organelle that has been linked to the Piwi-interacting RNA (piRNA) pathway. piRNAs are a class of gonadal-specific RNAs that are 23 29 nucleotides in length and protect genome stability by repressing the expression of deleterious retrotransposons. More recent studies in Drosophila have implicated the piRNA pathway in other functions including canalization of embryonic development, regulation of maternal gene expression and telomere protection. We have recently shown that Vasa (known as Mouse Vasa Homolog in mouse), a nuage component, plays a mitotic role in promoting chromosome condensation and segregation by facilitating robust chromosomal localization of condensin I in the Drosophila germline. Vasa functions together with Aubergine (a PIWI family protein) and Spindle-E/mouse TDRD-9, two other nuage components that are involved in the piRNA pathway, therefore providing a link between the piRNA pathway and mitotic chromosome condensation. Here, we propose and discuss possible models for the role of Vasa and the piRNA pathway during mitosis. We also highlight relevant studies implicating mitotic roles for RNAs and/or nuage in other model systems and their implications for cancer development.
\end{abstract}

\section{Introduction}

Germline granules were first described in rat spermatids more than 100 years ago and were subsequently named "chromatoid bodies" in mammalian cells [1,2]. They were later found to be widely-conserved in germline cells of many animals, where they are referred to as "nuage" and "P granules" in Drosophila melanogaster and Caenorhabditis elegans, respectively [3,4]. Under the electron microscope, germline granules appear as electron-dense fibrous structures, are not bound by any membrane and localize to the cytoplasmic peri-nuclear region [3]. Since their discovery, germline granules have remained mysterious due to the fact that their precise function has not been identified.

Recent studies in Drosophila have linked these germline granules (hereafter referred to as nuage) to a novel class of small non-coding RNAs known as Piwi-interacting RNAs (piRNAs). piRNAs are a class of gonadal-specific RNAs that are $\sim 23-29$ nucleotides in length and produced in a Dicer-independent manner [5-9]. They are mainly derived from transposons or repetitive sequences that are

\footnotetext{
* Correspondence: junwei@tll.org.sg; toshie@tll.org.sg

Department of Biological Sciences and Temasek Life Sciences Laboratory, 1 Research Link, The National University of Singapore, 117604, Singapore
}

clustered in the peri-centromeric and sub-telomeric regions of the chromosome [10,11]. Interestingly, many proteins that are required for the biogenesis of piRNAs are found to localize to the nuage. For example, in Drosophila, the PIWI subfamily proteins, Aubergine and Argonaute3, which bind piRNAs, are components of the nuage [11-14]. In mouse, the PIWI family proteins, MILI and MIWI, also localize to the chromatoid body [5]. In the Drosophila nuage, Aubergine and Argonaute3 are believed to function in a secondary piRNA amplification pathway known as the "ping-pong" cycle in germline cells $[11,15]$. Other germline piRNA pathway proteins, such as Vasa (Mouse Vasa Homolog), Spindle-E (mouse TDRD-9), Krimper, Maelstrom (mouse Maelstrom), Cutoff (yeast Rai1) and Tejas (mouse TDRD-5 and TDRD-7), also localize to nuage although their exactly molecular function in piRNA processing remains unknown [16-20]. Of note, some piRNA pathway components (Piwi, Rhino and Armitage/mouse MOV10L1) do not localize to nuage, but play a role in the primary production of germline piRNAs [21-24], and Maelstrom has an additional role in the nucleus to regulate germline stem cell differentiation [25].

The first identified role for the piRNA pathway is to repress deleterious retrotransposons and the repeated

\section{Biomed Central}


Stellate elements in the Drosophila germline [8,26,27]. This process appears to occur in part at the transcriptional level involving Piwi as the effector protein to promote heterochromatin formation [28-30]. It has also been proposed that post-transcriptional silencing of retrotransposons occurs at "pi-bodies" - cytoplasmic nuage in conjunction with Processing body components [31]. As germline cells function to give rise to the next generation, it is not difficult to imagine that they would adopt multiple mechanisms to protect their genome integrity.

Recent studies have shown that the piRNA pathway functions not only to repress transposons but also to regulate embryonic development and telomere protection. Studies of Heat Shock Protein 90 (Hsp90) and Piwi have linked the piRNA pathway to the canalization of embryonic development by consecutively suppressing genetic variation via an epigenetic mechanism and silencing transposon activity $[32,33]$. The piRNA pathway has also been shown to regulate deadenylation and decay of maternal mRNAs in the embryo [34], therefore implicating additional functions of the piRNA pathway outside the germline. Besides regulating gene expression, another emerging role of the piRNA pathway is to protect the telomeres by regulating the telomere capping complex and telomere length $[35,36]$. Therefore, we are only beginning to understand the functional roles of the piRNA pathway in various biological processes.

\section{Discussion}

\section{Nuage and the piRNA pathway in mitotic chromosome} condensation and segregation

We recently reported that in Drosophila, Vasa, a piRNA pathway component, promotes mitotic chromosome condensation and segregation by facilitating robust chromosomal localization of two condensin I components: CAP$\mathrm{H}$ (also known as Barren in Drosophila) and CAP-D2 [37]. Condensin complexes are major regulators of mitotic chromosomes that promote robust chromosome condensation and segregation [38,39]. vasa encodes a RNA helicase that is specifically expressed in germline cells $[12,40]$. Since its discovery in Drosophila, Vasa has been shown to be involved in various biological processes, including germline stem cell differentiation, piRNAmediated transposon silencing, pole-plasm assembly, and germline proliferation [17,40,41]. In Drosophila, Vasa functions in part by interacting with eukaryotic initiation factor 5B (eIF5B) to promote the expression of proteins required for proper differentiation including Mei-P26 [41]. In mouse, the Mouse Vasa Homolog has also been shown to regulate germline proliferation and piRNAmediated transposon silencing $[2,5,12]$.

We found that Vasa functions in an eIF5B-independent manner in promoting mitotic chromosome condensation and segregation in Drosophila [37]. During mitosis, Vasa forms mitotic bodies with Aubergine and Spindle-E (two other piRNA pathway proteins) and binds to piRNA-generating chromosomal loci at the peri-centromeric regions (Figure 1). In the piRNA pathway mutants, aubergine and spindle-E, chromosomal condensation and segregation were defective and concomitantly mitotic localization of Vasa is abolished. This suggests a link between the piRNA pathway and mitotic chromosome configuration. Furthermore, Vasa associates with CAP-H and CAP-D2, implying a direct role for Vasa in regulating their chromosomal localizations.

How does Vasa regulate condensin I localization? We hypothesize that Vasa may directly function to promote recruitment of condensin I during mitosis (Figure 2). This model is favored because it has been shown that during mitosis, CAP-H loading begins at centromeric regions and subsequently spreads distally towards the chromosomal arms [42]. During mitosis, Vasa localizes near peri-centromeric piRNA-generating loci possibly via Aubergine-bound piRNAs. This localized region consisting of Vasa (and also Spindle-E) promotes recruitment of CAP-H to the chromosomes. Our studies on the genetic and physical interaction between Vasa and condensin I components also support this model. It would be interesting to test the functional significance of the Vasa-CAP-H interaction to further refine this model. Another model which may also seem possible but is less supported is the idea that the Vasa/SpindleE/Aubergine-piRNA complex may localize to peri-centromeric piRNA-generating loci and stabilize CAP-H chromosomal localization (Figure 2). This model supposes a long-range action of Vasa on chromosomes by an unknown mechanism.

The involvement of Vasa and the piRNA pathway in germline mitotic chromosome regulation raises an intriguing question of whether an analogous pathway performs the same function in the soma. Although experimental evidence is lacking, recent studies suggest that an analogous somatic pathway may operate to promote condensin I localization. Somatic cells contain endogenous small interfering RNAs (endo-siRNAs) which function similarly to piRNAs in repressing retrotransposons [5]. Interestingly, some endo-siRNAs are derived from the same peri-centromeric loci that generate piRNAs [5], suggesting that these loci, together with the endo-siRNA pathway components, may collaborate in promoting condensin I recruitment in somatic cells. Another implication comes from a large-scale screen of localized RNAs in Drosophila embryos. A few retrotransposons (copia, Doc, and Ste12DOR) were identified to be localized onto mitotic chromosomes in developing embryos $[43,44]$. Therefore, it would be of interest to examine if the endo-siRNA pathway and a Vasa-related protein regulate condensin I in somatic cells. 


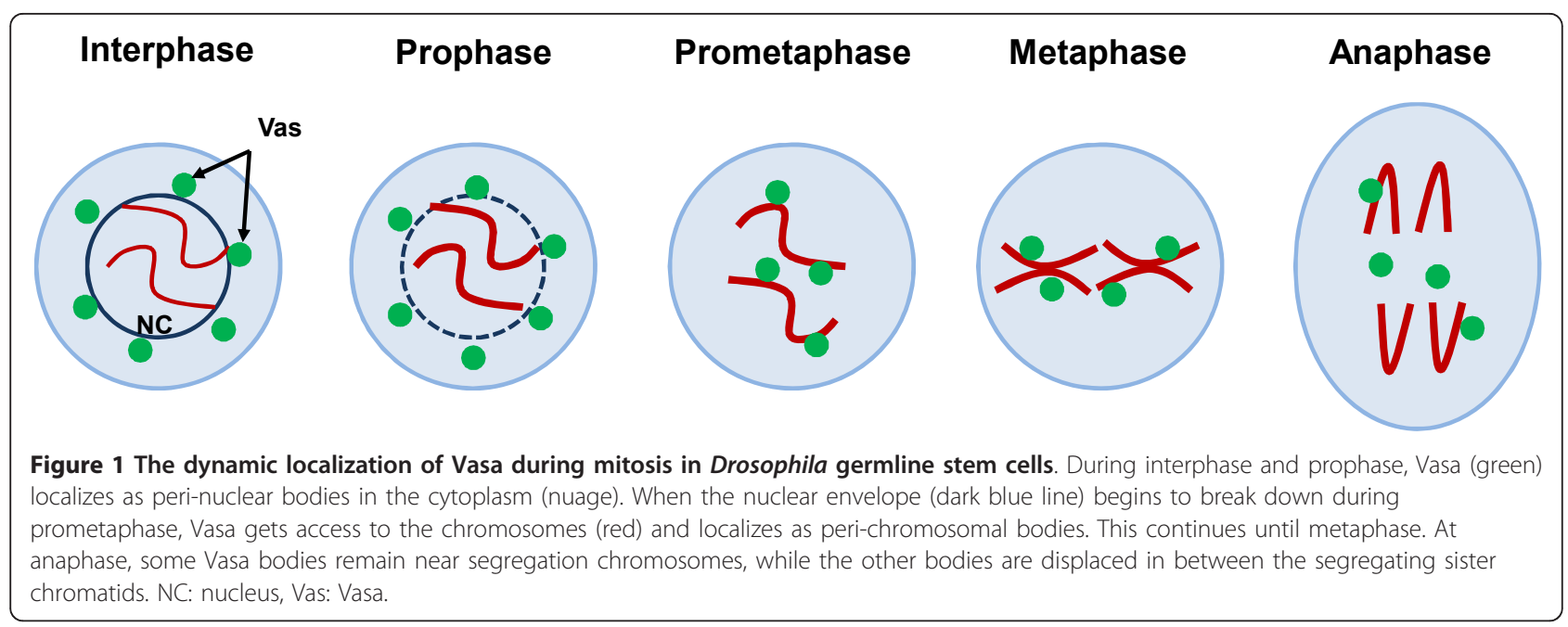

\section{Mitotic roles of germline granules and/or RNAs in other organisms}

Multiple lines of evidence for the role of germline granules and/or RNAs during mitosis have emerged over the past few years. Studies in C. elegans first demonstrated that some of the $\mathrm{P}$ granule (nuage equivalent) components, including Argonaute CSR-1, RNA-dependent RNA polymerase EGO-1, Dicer-related helicase DRH-3 and Tudor-domain protein EKL-1, promote chromosome segregation during mitosis by regulating proper chromosome organization in germline cells $[45,46]$. These proteins may form a mitotic complex that binds to CSR-1-interacting small RNAs (22G-RNAs) and localizes to mitotic holocentric chromosomes at the 22GRNA target loci. Therefore, the 22G-RNAs appear to mediate recruitment of proteins to the mitotic chromosomes to promote chromosome segregation. These observations are intriguingly similar to what we see in Drosophila, where we observe that the RNA helicase Vasa, the Tudor-domain-containing RNA helicase Spindle-E and the PIWI subfamily protein Aubergine all localize to mitotic chromosomes [37]. Despite the differences between the two systems, it seems that, in general, small non-coding RNAs and germline granules appear to play important roles in organizing chromosomal configuration in germline cells during cell division.

In addition to the dynamic localization of nuage/ $P$ granules during mitosis, cell cycle-dependent expression of non-coding RNAs has also been reported in Schizosaccharomyces pombe (fission yeast) and mouse [47-49]. In mouse, it was reported that satellite repeats from the pericentric heterochromatin were transcribed during mitosis, suggesting a mitotic role for such non-coding RNAs [47]. Interestingly, non-coding centromeric satellite repeats are shown to be a component of the chromosome passenger complex $(\mathrm{CPC})$ and potentiates
Aurora A kinase activity in murine cultured cells [50]. In yeast, centromeric repeats are transcribed during the $\mathrm{S}$ phase before the loading of condensin, suggesting that such non-coding RNAs may promote recruitment of condensin during mitosis to silence the expression of centromeric repeats in a cell cycle-dependent manner [48].

RNAs also appear to have some function not only in chromosomal configuration, but also in spindle formation. Studies in Xenopus laevis and human cell lines have shown that mRNAs localize to mitotic spindles and appear to have a function independent of protein coding during mitosis: regulating spindle assembly [51,52]. This further implicates the functional roles of RNAs, either short non-coding RNAs or mRNAs, in various processes, including but not limited to chromosome organization and spindle assembly, during mitosis.

\section{Disease implications}

Piwi, a founding member of the piRNA pathway, was originally found to regulate stem cell division in the Drosophila germline [53]. It was also reported that human and mouse Piwi homologues, Hiwi, PiwiL2, and PiwiL2-like proteins, are expressed in certain human and mouse stem cells and tumors [54-57], raising the possibility that the development of cancer may be linked to the piRNA pathway and stem cells. Using the Drosophila brain as a model system, a recent study indeed demonstrated that ectopic expression of germline and piRNA pathway genes are responsible for formation and development of brain tumors [58]. Although the mechanisms of how the piRNA pathway promotes tumorigenesis remain unknown, these data highlight the importance of understanding the role of the piRNA pathway during somatic cell division, with the idea that this pathway may be a target for cancer therapeutics. 
A

Recruitment model

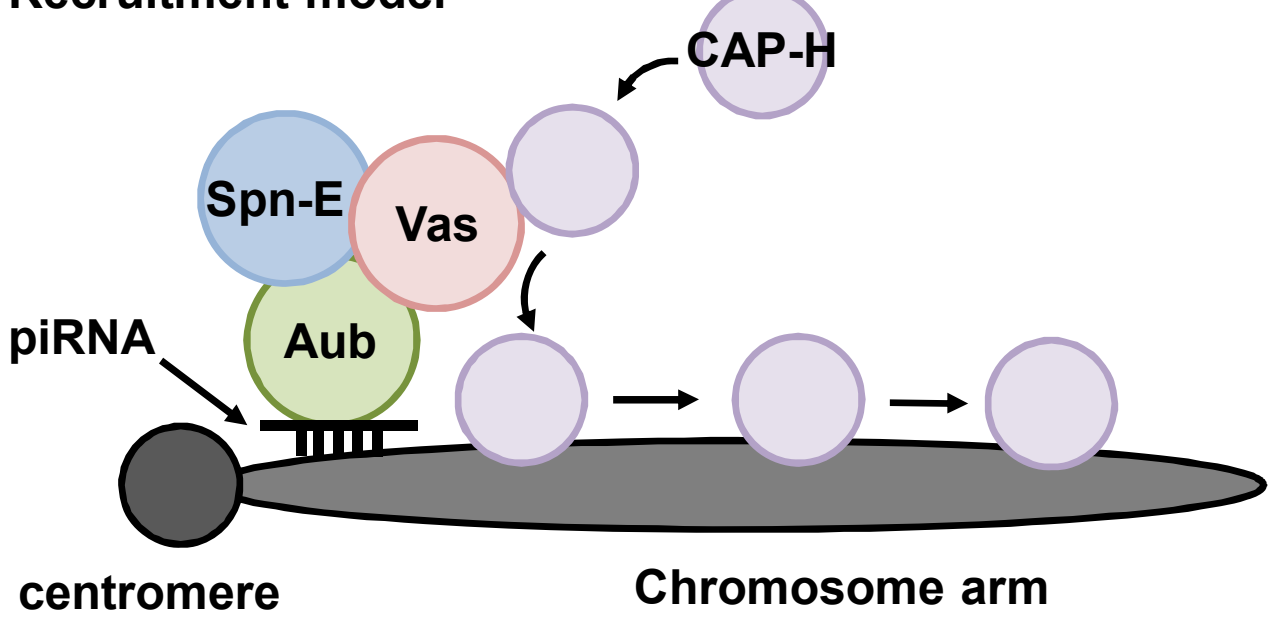

B

\section{Stabilization model}

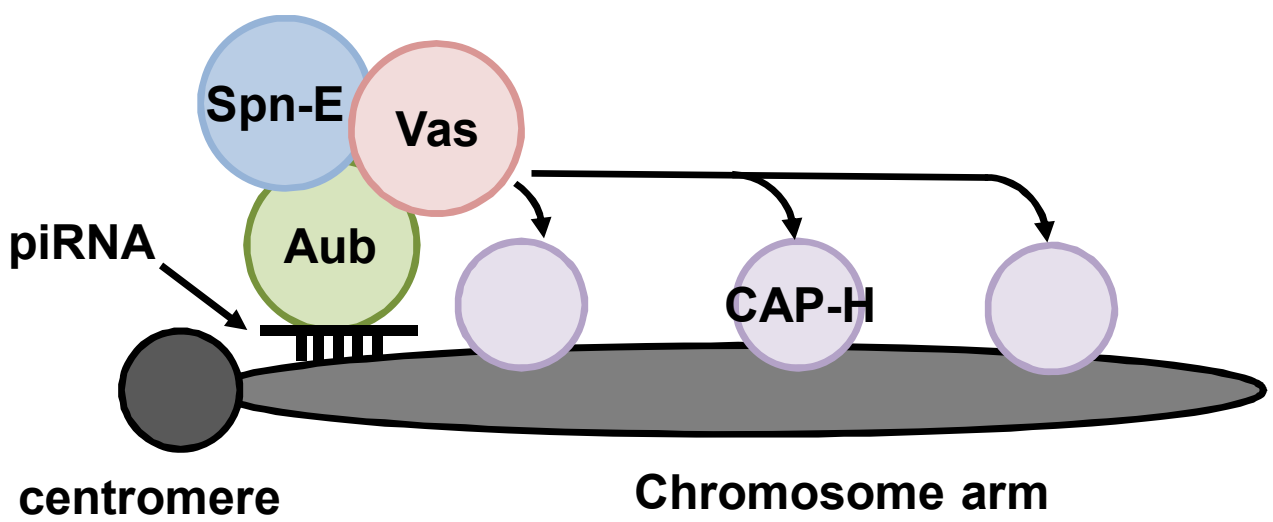

Figure 2 Proposed mechanisms by which Vasa regulates condensin I (CAP-H) localization. (A) The Recruitment model: Vasa functions primarily to recruit CAP-H at the peri-centromeric regions. After CAP-H loading, it spreads to the distal chromosome arms. (B) The Stabilization model: At the peri-centromeric region, Vasa functions in a yet unknown mechanism to promote a stable association of CAP-H to the mitotic chromosomes. Aub: Aubergine, Spn-E: Spindle-E.

\section{Conclusions}

Our recent work on the role of Vasa and the piRNA pathway in promoting chromosome condensation and segregation during mitosis provides one example of a mitotic role for non-coding RNAs. Similar roles for such non-coding RNAs have also been described in various model organisms, including yeast, C. elegans, Xenopus and mouse. Future studies would likely uncover more examples of the fascinating interplay between RNAs and the cell cycle.
List of abbreviations used

mRNA: messenger RNA; piwi: P-element induced wimpy testis.

\section{Acknowledgements and Funding}

This research was supported by the Temasek Life Sciences Laboratory and the Singapore Millennium Foundation.

\section{Authors' contributions}

JWP and TK drafted, read and approved the manuscript.

\section{Competing interests}

The authors declare that they have no competing interests. 
Received: 10 February 2011 Accepted: 28 February 2011

Published: 28 February 2011

\section{References}

1. Yokota S: Historical survey on chromatoid body research. Acta Histochem Cytochem 2008, 41:65-82.

2. Kotaja N, Sassone-Corsi P: The chromatoid body: a germ-cell-specific RNAprocessing centre. Nat Rev Mol Cell Biol 2007, 8:85-90.

3. Eddy EM: Germ plasm and the differentiation of the germ line. Int Rev Cytol 1975, 43:229-281.

4. Updike D, Strome S: P granule assembly and function in Caenorhabditis elegans germ cells. J Androl 2010, 31:53-60.

5. Saito K, Siomi MC: Small RNA-mediated quiescence of transposable elements in animals. Dev Cell 2010, 19:687-697.

6. Senti KA, Brennecke J: The piRNA pathway: a fly's perspective on the guardian of the genome. Trends Genet 2010, 26:499-509.

7. Khurana JS, Theukauf W: piRNAs, transposon silencing, and Drosophila germline development. J Cell Biol 2010, 191:905-913.

8. Vagin W, Sigova A, Li C, Seitz H, Gvozdev V, Zamore PD: A distinct small RNA pathway silences selfish genetic elements in the germline. Science 2006, 313:320-324

9. Aravin AA, Lagos-Quintana M, Yalcin A, Zavolan M, Marks D, Snyder B, Gaasterland T, Meyer J, Tuschl T: The small RNA profile during Drosophila melanogaster development. Dev Cell 2003, 5:337-350.

10. Saito K, Nishida KM, Mori T, Kawamura Y, Miyoshi K, Nagami T, Siomi T, Siomi MC: Specific association of Piwi with rasiRNAs derived from retrotransposon and heterochromatic regions in the Drosophila genome. Genes Dev 2006, 20:2214-2222.

11. Brennecke J, Aravin AA, Stark A, Dus M, Kellis M, Sachidanandam R, Hannon GJ: Discrete small RNA-generating loci as master regulators of transposon activity in Drosophila. Cell 2007, 128:1089-1103.

12. Arkov AL, Ramos A: Building RNA-granules: insight from the germline. Trends Cell Biol 2010, 20:482-490.

13. Nishida KM, Saito K, Mori T, Kawamura Y, Nagami-Okada T, Inagaki S, Siomi H, Siomi MC: Gene silencing mechanisms mediated by Aubergine piRNA complexes in Drosophila male gonad. RNA 2007, 13:1911-1922.

14. Nagao A, Mituyama $T$, Huang $H$, Chen D, Siomi MC, Siomi H: Biogenesis pathways of piRNAs loaded onto AGO3 in the Drosophila testis. RNA 2010, 16:2503-2515.

15. Gunawardane LS, Saito K, Nishida KM, Miyoshi K, Kawamura $Y$, Nagami T, Siomi H, Siomi MC: A slicer-mediated mechanism for repeat-associated siRNA $5^{\prime}$ end formation in Drosophila. Science 2007, 315:1587-1590.

16. Vagin W, Klenov MS, Kalmykova Al, Stolyarenko AD, Kotelnikov RN, Grozdev VA: The RNA interference proteins and vasa locus are involved in the silencing of retrotransposons in the female germline of Drosophila melanogaster. RNA Biol 2004, 1:54-58.

17. Lim AK, Kai T: Unique germ-line organelle, nuage, functions to repress selfish genetic elements in Drosophila melanogaster. Proc Natl Acad Sci USA 2007, 104:6714-6719.

18. Patil VS, Kai T: Repression of retroelements in Drosophila germline via piRNA pathway by the Tudor domain protein Tejas. Curr Biol 2010, 20:724-730.

19. Findley SD, Tamanaha M, Clegg NJ, Ruohola-Baker H: Maelstrom, a Drosophila spindle-class gene, encodes a protein that colocalizes with Vasa and RDE1/AGO1 homolog, Aubergine, in nuage. Development 2003, 130:859-871.

20. Chen $Y$, Pane A, Schupbach T: cutoff and aubergine mutations result in retrotransposon upregulation and checkpoint activation in Drosophila. Curr Biol 2007, 17:637-642.

21. Saito $K$, Inagaki $S$, Mituyama $T$, Kawamura $Y$, Ono $Y$, Sakota $E$, Kotani $H$, Asai K, Siomi H, Siomi MC: A regulatory circuit for piwi by the large Maf gene traffic jam in Drosophila. Nature 2009, 461:1296-1299.

22. Klattenhoff $\mathrm{C}, \mathrm{Xi} \mathrm{H}$, Li C, Lee $\mathrm{S}$, Xu J, Khurana JS, Zhang F, Schultz N, Koppetsch BS, Nowosielska A, Seitz H, Zamore PD, Weng Z, Theurkauf WE: The Drosophila HP1 homolog Rhino is required for transposon silencing and piRNA production by dual-strand clusters. Cell 2009, 138:1137-1149.

23. Malone CD, Brennecke J, Dus M, Stark A, McCombie WR, Sachidanandam R, Hannon GJ: Specialized piRNA pathways act in germline and somatic tissues of the Drosophila ovary. Cell 2009, 137:522-535.
24. Li C, Vagin W, Lee $S, X u J$, Ma S, Xi H, Seitz H, Horwich MD, Syrzycka M, Honda BM, Kittler EL, Zapp ML, Klattenhoff C, Schulz N, Theurkauf WE, Weng Z, Zamore PD: Collapse of germline piRNAs in the absence of Argonaute3 reveals somatic piRNAs in flies. Cell 2009, 137:509-521.

25. Pek JW, Lim AK, Kai T: Drosophila Maelstrom ensures proper germline stem cell lineage differentiation by repressing microRNA-7. Dev Cell 2009, 17:417-424.

26. Aravin AA, Klenov MS, Vagin W, Bantignies F, Cavalli G, Gvozdev VA Dissection of a natural RNA silencing process in the Drosophila melanogaster germ line. Mol Cell Biol 2004, 24:6742-6750.

27. Aravin AA, Naumova NM, Tulin AV, Vagin W, Rozovsky YM, Gvozdev VA: Double-stranded RNA-mediated silencing of genomic tandem repeats and transposable elements in the D. melanogaster germline. Curr Biol 2001, 11:1017-1027.

28. Yin $\mathrm{H}$, Lin $\mathrm{H}$ : An epigenetic activation role of Piwi and a Piwi-associated piRNA in Drosophila melanogaster. Nature 2007, 450:304-308.

29. Brower-Toland B, Findley SD, Jiang L, Liu L, Yin H, Dus M, Zhou P, Elgin SC, Lin H: Drosophila PIWI associates with chromatin and interacts with HP1a. Genes Dev 2007, 21:2300-2311.

30. Klenov MS, Lavrov SA, Stolyarenko AD, Ryazansky SS, Aravin AA, Tuschl T, Gvozdev VA: Repeat-associated siRNAs cause chromatin silencing of retransposons in the Drosophila melanogaster germline. Nucleic Acids Res 2007, 35:5430-5438.

31. Lim AK, Tao L, Kai T: piRNAs mediate posttranscriptional retroelement silencing and localization to pi-bodies in the Drosophila germline. J Cell Biol 2009, 186:333-342.

32. Specchia V, Piacentini L, Tritto P, Fanti L, D'Alessandro R, Palumbo G, Pimpinelli S, Bozzetti MP: Hsp90 prevents phenotypic variation by suppressing the mutagenic activity of transposons. Nature 2010, 463:662-665

33. Gangaraju VK, Yin H, Weiner MM, Wang J, Huang XA, Lin H: Drosophila Piwi functions in Hsp90-mediated suppression of phenotypic variation. Nat Genet 2011, 43:153-158.

34. Rouget C, Papin C, Boureux A, Meunier AC, Franco B, Robine N, Lai EC, Pelisson A, Simonelig M: Maternal mRNA deadenylation and decay by the piRNA pathway in the early Drosophila embryo. Nature 2010, 467:1128-1132.

35. Khurana JS, Xu J, Weng Z, Theurkauf WE: Distinct functions for the Drosophila piRNA pathway in genome maintenance and telomere protection. PLoS Genet 2010, 6:e1001246.

36. Savitsky M, Kwon D, Georgiev P, Kalmykova A, Gvozdev V: Telomere elongation is under the control of the RNAi-based mechanism in the Drosophila germline. Genes Dev 2006, 20:345-354.

37. Pek JW, Kai T: A role for Vasa in regulating mitotic chromosome condensation in Drosophila. Curr Biol 2011, 21:39-44.

38. Hirano T: Condensins: organizing and segregating the genome. Curr Biol 2005, 15:R265-275

39. Hudson DF, Marshall KM, Earnshaw WC: Condensin: architect of mitotic chromosomes. Chromosome Res 2009, 17:131-144.

40. Styhler S, Nakamura A, Swan A, Suter B, Lasko P: vasa is required for GURKEN accumulation in the oocyte, and is involved in oocyte differentiation and germline cyst development. Development 1998, 125:1569-1578.

41. Liu N, Han H, Lasko P: Vasa promotes Drosophila germline stem cell differentiation by activating mei-P26 translation by directly interacting with a (U)-rich motif in its 3'UTR. Genes Dev 2009, 23:2742-2752.

42. Oliveira RA, Heidmann S, Sunkel CE: Condensin I binds chromatin early in prophase and displays a highly dynamic association with Drosophila mitotic chromosomes. Chromosoma 2007, 116:259-274.

43. Lécuyer E, Yoshida H, Parthasarathy N, Alm C, Babak T, Cerovina T, Hughes TR, Tomancak P, Krause HM: Global analysis of mRNA localization reveals a prominent role in organizing cellular architecture and function. Cell $2007,131: 174-187$.

44. Lécuyer $E$, Yoshida H, Krause HM: Global implications of mRNA localization pathways in cellular organization. Curr Opin Cell Biol 2009, 21:409-415.

45. van Wolfswinkel JC, Claycomb JM, Batista PJ, Mello CC, Berezikov E, Ketting RF: CDE-1 affects chromosome segregation through uridylation of CSR-1-bound siRNAs. Cell 2009, 139:135-148.

46. Claycomb JM, Batista PJ, Pang KM, Gu W, Vasale JJ, van Wolfswinkel JC, Chaves DA, Shirayama M, Mitani S, Ketting RF, Conte D Jr, Mello CC: The 
argonaute CSR-1 and its 22G-RNA cofactors are required for holocentric chromosome segregation. Cell 2009, 139:123-134.

47. Lu J, Gilbert DM: Proliferation-dependent and cell cycle-regulated transcription of mouse pericentric heterochromatin. J Cell Biol 2007, 179:411-421.

48. Chen ES, Zhang K, Nicolas E, Cam HP, Zofall M, Grewal SIS: Cell cycle control of centromeric repeat transcription and heterochromatin assembly. Nature 2008, 451:734-737.

49. Lu J, Gilbert DM: Cell cycle regulated transcription of heterochromatin in mammals vs. fission yeast. Cell Cycle 2008, 7:1907-1910.

50. Ferri F, Bouzinba-Segard H, Velasco G, Hube F, Francastel C: Non-coding murine centromeric transcripts associate with and potentiate Aurora B kinase. Nucleic Acids Res 2009, 37:5071-5080.

51. Blower MD, Nachury M, Heald R, Weis K: A Rae1-containing ribonucleoprotein complex is required for mitotic spindle assembly. Cell 2005, 121:223-234

52. Blower MD, Feric E, Weis K, Hearld R: Genome-wide analysis demonstrates conserved localization of messenger RNAs to mitotic microtubules. J Cell Biol 2007, 179:1365-1373.

53. Cox DN, Chao A, Lin H: piwi encodes a nucleoplasmic factor whose activity modulates the number and division rate of germline stem cells. Development 2000, 127:503-514.

54. Sharma AK, Nelson MC, Brandt JE, Wessman M, Mahmud N, Weller KP, Hoffman R: Human CD34+ stem cells express the hiwi gene, a human homologue of the Drosophila gene piwi. Blood 2001, 97:426-434.

55. Ye Y, Yin D-T, Chen L, Zhou Q, Shen R, He G, Yan Q, Tong Z, Issekutz AC, Shapiro CL, Barsky SH, Lin H, Li J-J, Gao J-X: Identification of Piwil2-Like (PL2L) proteins that promote tumorigenesis. PLOS ONE 2010, 5:e13406.

56. Qiao D, Zeeman A-M, Deng W, Looijenga LHJ, Lin H: Molecular characterization of hiwi, a human member of the piwi gene family whose overexpression is correlated to seminomas. Oncogene 2002, 21:3988-3999.

57. Wu Q, Ma Q, Shehadeh LA, Wilson A, Xia L, Yu H, Webster KA: Expression of the Argonaute protein PiwiL2 in adult mouse mesenchymal stem cells. Biochem Biophys Res Commun 2010, 396:915-920.

58. Janic A, Mendizabal L, Llamazares S, Rossell D, Gonzalez C: Ectopic expression of germline genes drives malignant brain tumor growth in Drosophila. Science 2010, 330:1824-1827.

doi:10.1186/1747-1028-6-6

Cite this article as: Pek and Kai: Non-coding RNAs enter mitosis:

functions, conservation and implications. Cell Division 2011 6:6.

\section{Submit your next manuscript to BioMed Central and take full advantage of:}

- Convenient online submission

- Thorough peer review

- No space constraints or color figure charges

- Immediate publication on acceptance

- Inclusion in PubMed, CAS, Scopus and Google Scholar

- Research which is freely available for redistribution

Submit your manuscript at www.biomedcentral.com/submit 